\title{
CONTROL AND INTERACTION ALGORITHMS FOR INDUSTRIAL AND SERVICE ROBOTS
}

\author{
ARYSKIN ALEXANDER, BOGDANOVICH ALENA, DAVYDOV \\ OLEG, KHELEMENDIK ROMAN, PETRAKOV MAKSIM, \\ PRYANICHNIKOV VALENTIN \& TARASOV RADOMIR
}

Abstract: The paper is considering the design of a transport workshop according to the concept Industry 4.0. At the stage of development and design of the transport system, the main attention was focused on the mPC and sensors frequencies coordination and the problem of accurate positioning. To organize timely stopping and accurate positioning of the trolley, it was used a set of proximity switches with a special processing programs for data transfer, filtering and simulation. Creating of efficient electronics to control transport robots is considered.

Key words: mobile and service robots, Industry 4.0, sensorics, Amur-307
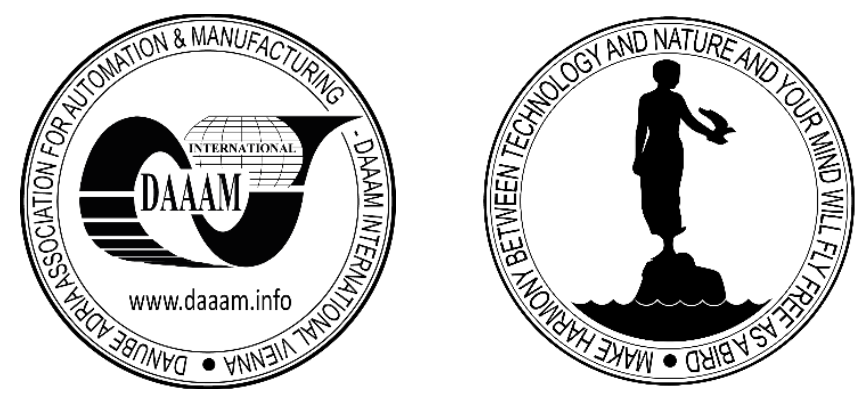

Authors' data: $\mathrm{PhD}$ student Aryskin, $\mathrm{A}[\mathrm{lexander}]^{* *}$; PhD student Bogdanovich**, $\mathrm{A}$ [lena]; PhD student Davydov, O[leg]**; PhD, dr. Khelemendik, R[oman]*; PhD student Petrakov, M[aksim] ${ }^{* *}$; d.tech.sc., univ.prof., head of Chair Pryanichnikov, V[alentin] *_***; PhD student Tarasov R[adomir]*, * Keldysh Institute of Applied Mathematics RAS, Miusskaya sq., 4,125047, Moscow, Russia, ** MSTU "Stankin", *** IINET RSUH Miusskaya sq., 6, Moscow, Russia

This Publication has to be referred as: Aryskin, A[leksander] A[.]; Bogdanovich, A[lena]; Davydov, O[leg]; Khelemendik, R[oman]; Petrakov, M[axim] \& Pryanichnikov, V[alentin] (2019). Control and Interaction Algorithms for Industrial and Service Robots, Chapter 33 in DAAAM International Scientific Book 2019, pp.377-384, B. Katalinic (Ed.), Published by DAAAM International, ISBN 978-3902734-24-2, ISSN 1726-9687, Vienna, Austria

DOI: $10.2507 /$ daaam.scibook.2019.33 
Aryskin, A. A.; Bogdanovich, A.; Davydov, O.; Khelemendik, R.; Petrakov, M. \& ...

\section{Introduction}

At the stage of development and design of the transport system, which is part of the Industry 4.0 concept, the main attention was required to pay to the problem of the exact positioning of moving units within $7 \mathrm{~mm}$ and further change of motion direction. Based on theoretical consideration, it was decided to use a set of proximity switch of 2 types to organize timely stopping and accurate positioning of the trolleys. The sensors are interacts with the scale "pulse rulers" and the special radio marks.

To control the transport department of the shop, it was necessary to assemble an automation sets, build the shop structure, including data transfer from the lower level to the upper one using various data protocols, and develop the software.

We also developed electronics for the Amur-307 robot, which is part of the telecommunication and service complex.

\section{Design of a special industry}

The transition to the concept of Industry 4.0 involves the computerization of the entire production environment, the processes of logistics, as well as the active use of the Internet in production. In this paper, we consider the main elements of "smart production". The work of the transport shop is based on mobile trolleys moving along the rails in the direction of the positions, depending on the performance of a particular operation on the production line. Each trolley is able to transport the material poured into it, to a certain place depending on the cycle of work, and return to the starting position.

One of the main tasks of the design of the transport line was the technological process associated with the solidification of the material in the carts during their passage along the conveyor in the drying chambers. This system has several zones of preparation and transportation of material: 1. Position of the preparation area of the filling mass, which prepares the transported mass for the trucks; 2. Position under reactors load pour liquid mass into the forms on trollys; 3 . Position - hardening of the mass in the trucks. At this stage, the carts are moved to the next destination, during the passage of which the material solidifies; 4 . Position during the passage of which poured mass; 5. Position for return of the cart to the initial state, i.e. to position 2 , for filling of new mass.

This system consists of mechatronic subsystems, such as: bogies in conjunction with rail guides (Fig. 1), electric motors control systems, electronic power and control units, inductive sensors and measuring equipment (Fig.2).

At the stage of development and design of this system, the main attention was required to pay to the problem of accurate positioning. Based on simulation, we organized the timely stoppung and accurate positioning. The sensor part of the sensor interacts with the scale of the " pulse ruler. This line is a rod with evenly distributed metal billets insulated with plastic polymer. 

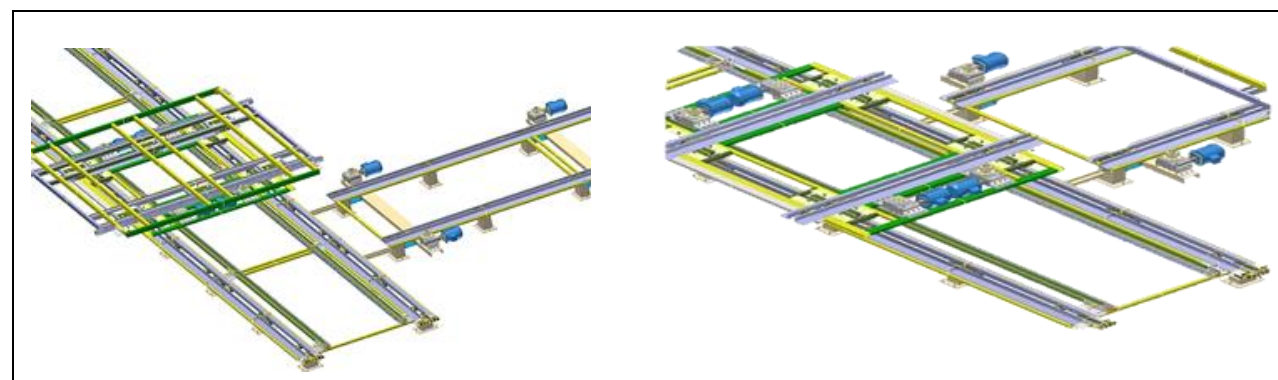

Fig.1. Rail guides

Fig. .2. Electric motors and sensor

The operation of this sensor is that the passage of the pulse line produces a number of signals transmitted to the local control device. This device in the course of mathematical analysis, sends a control command to the central programmable logic controller, where a signal is formed to accelerate or brake the engine. In the presented image, taking into account the distance between the "check points". D1 is the distance from the inductive sensor to the pulse ruler and it's variations are covered by processing algorithm. To test it, the mathematical model was created in the program Matlab Simulink. The main blocks included in the mathematical model are: motor block friction function block, control signal block. The simulation of the system with the control step signal was carried out, the results in the paper on the Symposium DAAAM-2019. Based on this results, it is possible to conclude, that influence of various parameters on system is not big. Because of the too fast processes, the braking of the cart is almost instantaneous, in consequence of which the braking distance is too small.

To organize the automation of the industrial cycle was designed and assembled control equipment on the basis of industrial PLC. The exterior of the control unit is shown in (Fig.3).

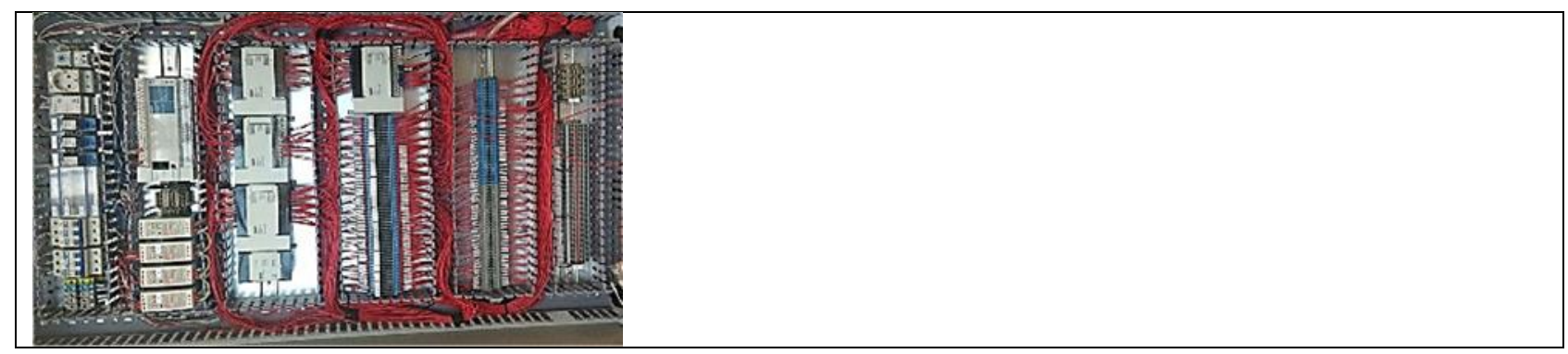

Fig. 3 The control unit for transport part of the shop.

The automation includes power supplies, circuit breakers, diode decoupling, programmable logic controllers expansion modules and additional fast processors. It allows both manual and automatic control. In manual mode it's automatically recording of all operator's motions, that give the opportunity to creating recipes. Simultaneously with the control of the production process, the industrial cycle program with logical analysis is monitoring the operator actions. In the framework of this algorithms, the specialized environment for the developing and debugging of software for programmable logic controllers - CODESYS was used.

The architecture of this enterprise is shown in (Fig. 4). 


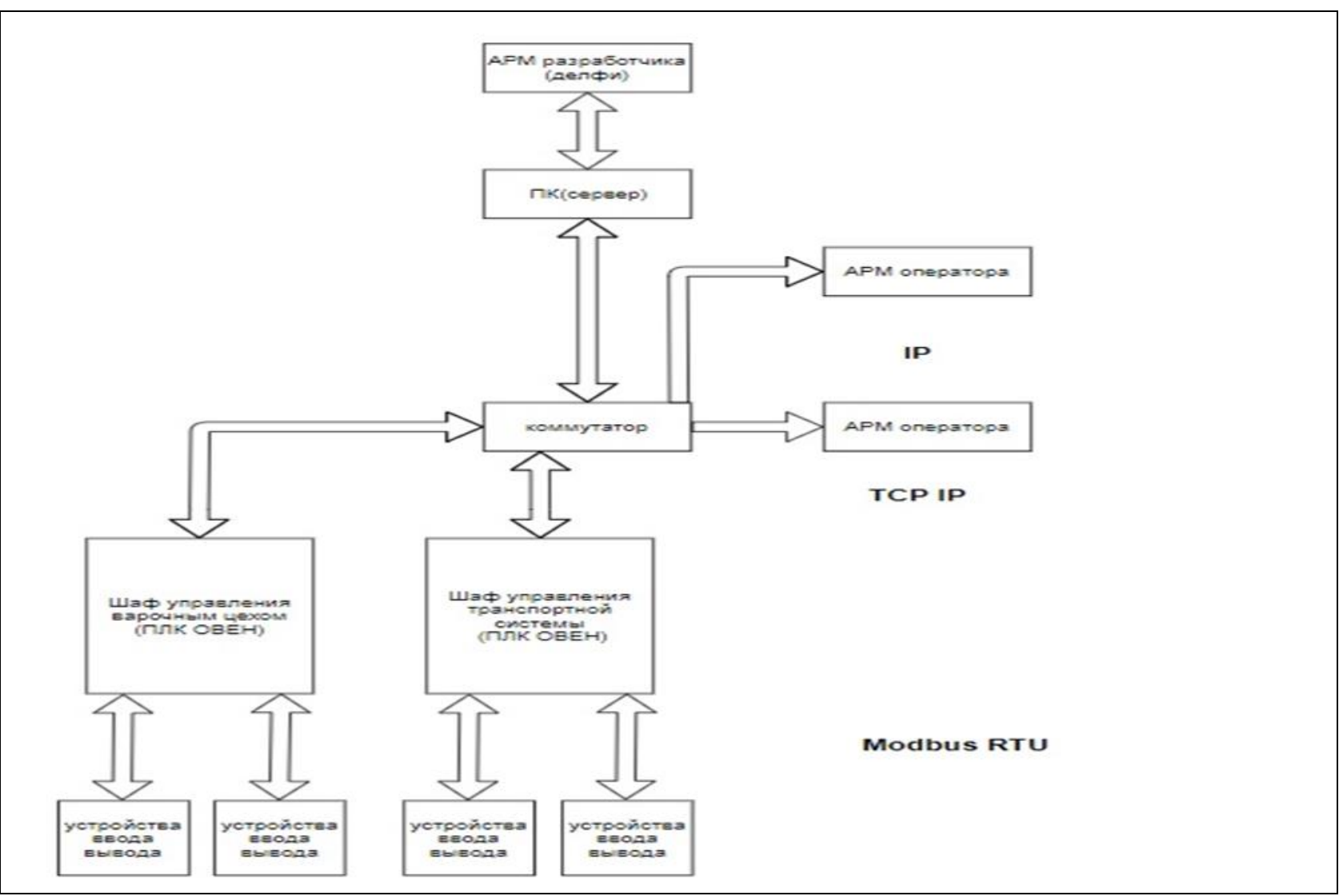

Fig.4. System architecture

\section{Implementation of service robot Amur-307}

Basing on the listed experience in synchronizing the data flows in $\mathrm{mPC}$ we realized the project Amur-307 service robot for complex maintenance of internal premises of polyclinics [1]. This robot has a crawler drive and mounted custom manipulator with which the robot interacts with the surrounding objects [4]. The sensors of the robot are: a wide-angle FullHD camera and/or 3D-camera with perprocessing on $\mathrm{mPC}, 6$ encoders for odometry and spatial orientation of the manipulator, a 3+6 dof inertial sensor, an atmospheric pressure sensor, lidar and an a set of ultrasonic and contact sensors (Fig. 5)

Raspberry mPC was chosen as a computing platform due to its, availability and availability [6]. The Moto Shields motor drivers have a large adjustable current 30A. To ensure energy efficiency and simplicity of construction, the motors of the manipulator of different links were connected through a relay, thus of the two motors of the manipulator on each side at a particular time, only one works. Since the motors have a worm gear, when the motor is switched off, it does not change its axial position. 


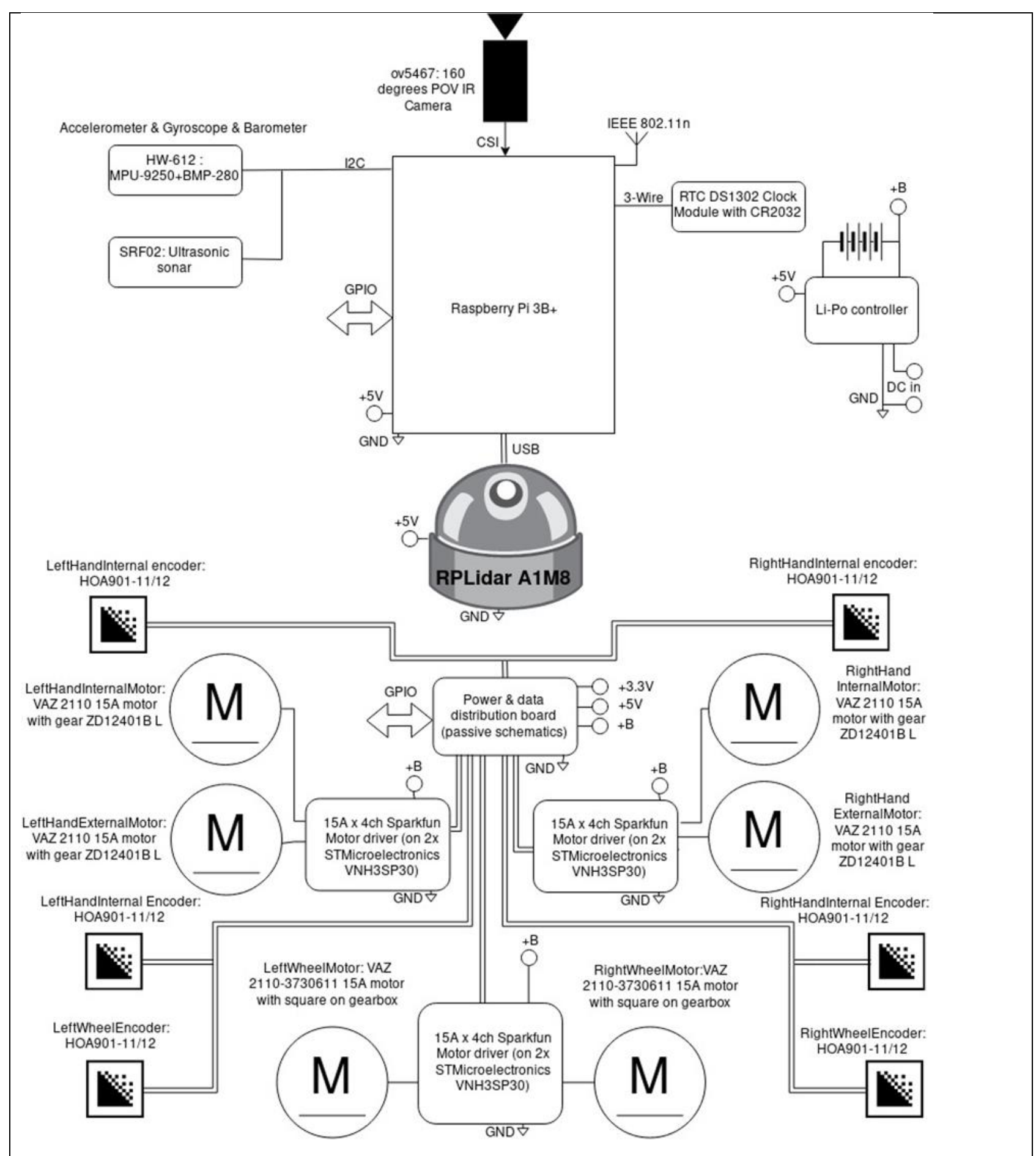

Fig.5. Block diagram of the on-board electronics of the Amur-307

ADC modules were also used, for processing the current sensors from motor drivers, as well as to read the manipulator encodes. Since each motor driver requires independent PWM channels, we use a hardware implementation of DMA and 2 hardware PWM ports from $\mathrm{mPC}$ and input and output signal lines (2 types) parallelto-serial to connect motors and encoders. The real-time clock system, is supporting our algorithm of synchronizing data flows.

For supervisory control of the robots and communications with a stationary control and monitoring center, are used two independent channels with different protocols. The robot is powered by an onboard lithium-polymer battery with 
Aryskin, A. A.; Bogdanovich, A.; Davydov, O.; Khelemendik, R.; Petrakov, M. \& ...

stabilized voltages: $5 \mathrm{~V} / 2 \mathrm{~A}$ and $12 \mathrm{~V} / 10 \mathrm{~A}$ (maximum pulse current up to $550 \mathrm{~A}$ ), with a capacity of $12000 \mathrm{mAh}$.

A prototype of the electronics for this robot was developed, which allows quick replacement of modules and other parts in case of malfunctions. Also in the PCB was installed a connectors for motors, for the possibility of moving the robot in case of failure of the control electronics (only $12 \mathrm{~V}$ power is required). The layout diagram on PCB board modules was also formed (Fig.6).

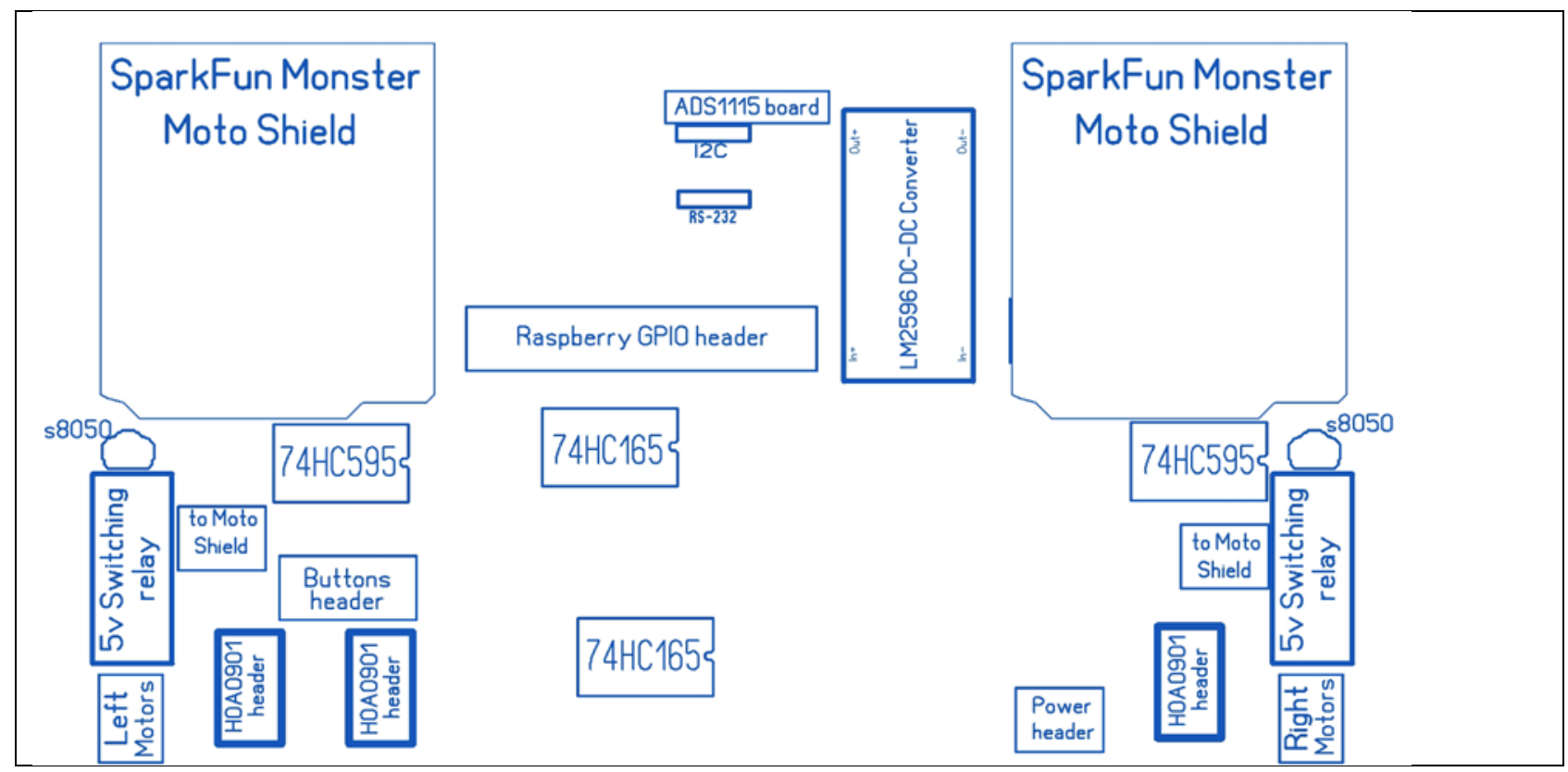

Fig.6. Layout of modules and parts on the board

\section{Conclusion}

In the course of the work, the transport workshop system was designed and developed, implemented on the basis of the Industry 4.0 concept. One of the main problems identified was the exact positioning of the trolley. Based on theoretical tests, in order to achieve the desired result, it was developed a an interesting sensor devise, made in the form of a ruler and a contact unit. To control the workshop, an automation equipment was built, as well as the architecture of the enterprise was built, and the required software was written in the CoDeSys environment.

When designing electronics for the Amur-307 robot, which is part of the Amur telecommunications complex, a structural electrical circuit was formed. A circuit diagram was also developed with the layout of the elements of the distribution board, with the subsequent implementation of the prototype.

The listed works take there part in the main results of our project "Intelligent robotronics". They were tested and implemented in practice, also were published during last 3 years in 38 articles (14 Scopus), 2 patents and one Russian State Standard on robots and robotic devices (methods of programming and interacting with operators). Some of the references are below [1-14]. 


\section{References}

Davydov D.V., Eprikov S.R., Kirsanov K.B., Pryanichnikov V.E. (2017). Service Robots Integrating Software and Remote Reprogramming, Proceedings of the 28th DAAAM International Symposium, pp.1234-1240, B. Katalinic (Ed.), Published by DAAAM International, ISBN 978-3-902734-11-2, ISSN 1726-9679, Vienna, Austria DOI: $10.2507 / 28$ th.daaam.proceedings.172.

Pryanichnikov V.E., Katalinic B., Kirilchenko A.A., Khelemendik R.V., Kuvshinov S.V., Vician D., Uglesic A. New Creative Educational Technologies for Interuniversity Network // 25th DAAAM International Symposium on Intelligent Manufacturing and Automation. 2014. — Procedia Engineering. 2015. - Vol. 100, P.259-268.

URL: http://www.sciencedirect.com/science/article/pii/S1877705815003938

Pryanichnikov V.E., Chernyshev V.V., Arykantsev V.V., Aryskin A.A., Eprikov S.R., Ksenzenko A.Ya., Petrakov M.S. (2018). Enhancing the Functionality of the Groups of Autonomous Underwater Robots, Proceedings of the 29th DAAAM International Symposium, pp.1319-1325, B. Katalinic (Ed.), Published by DAAAM International, ISBN 978-3-902734-20-4, ISSN 1726-9679, Vienna, Austria DOI: 10.2507/29th.daaam.proceedings. 190

Pryanichnikov V. E., Bielic T., Vican D., Katalinich B., Kirsanov K. B., Kuvshinov S. V., Marzanov Yu., Poduraev J. V., Khelemendik R. V., Prysev E. A., Uglesic A., Kharin K.V. Development of educational technology and the network of associated laboratories of robotarium // Information-measuring and control system. - 2015. Vol. 13, No. 7. - Pp. 7-25. ISSN 2070-0814.

Khelemendik R. V., Pryanichnikov V. E. On IGEC technology and its application in the study of chess endings // Scientific service on the Internet: Proceedings of the XIX all-Russian scientific conference (September 19-24, 2017, Novorossiysk). - Moscow: KIAM Keldysh Inst., 2017.2 Pp. 446-455. - URL: http://keldysh.ru/abrau/2017/proc.pdf

Shipovalov E. A., Pryanichnikov V. E. Auto-planning of missions of mobile robots by onboard computer complexes with hybrid architecture // Extreme robotics. / Collection of abstracts of the International scientific and technical conference. - St. Petersburg: Publishing and printing complex "Gangut", 2017. - Pp. 119-120.6.

Kirilchenko A. A., Pryanichnikov V. E., Rogozin K. V. Limits of reliability and reliability of evidence. Skepticism in mathematics, functions, traditions // Informationmeasuring and control systems. - 2013. - Vol. 11, No. 4. Pp. 57-65. ISSN 2070-0814. Pryanichnikov V. E. Artificial intelligence and software and hardware robotic systems. Information-measuring and control systems. - 2018. - Vol. 16, No. 12. - Pp. 3-11. ISSN 2070-0814.

Kuvshinov S. V., Pryanichnikov V. E., Khelemendik R. V., Kharin K. V., Eprikov S. R. Robotariums: scientific and technological base of "Intelligent robotronics" / / Information-measuring and control systems. - 2018. — Vol. 16, No. 12. Pp. 12-23. ISSN 2070-0814.

Pryanichnikov V.E., Aryskin A.A., Eprikov S.R., Kirsanov K.B., Khelemendik R.V., Ksenzenko A.Ya., Prysev E.A., Travushkin A. S. (2017). Technology of Multi-Agent 
Aryskin, A. A.; Bogdanovich, A.; Davydov, O.; Khelemendik, R.; Petrakov, M. \& ...

Control for Industrial Automation with Logical Processing of Contradictions, Proceedings of the 28th DAAAM International Symposium, pp.1202-1207, B. Katalinic (Ed.), Published by DAAAM International, ISBN 978-3-902734-11-2, ISSN 1726-9679, Vienna, Austria.

DOI:10.2507/28th.daaam.proceedings.167

Pryanichnikov V.E., Ksenzenko A.Ya., Kuvshinov S. V., Poduraev Yu. V., Prysev E.A., Khelemendik R.V., Eprikov S. (2016). Intelligent robotronics: hardwaresoftware complexes of robotariums, Proceedings of the 27th DAAAM International Symposium, pp.0225-0229, B. Katalinic (Ed.), Published by DAAAM International, ISBN 978-3-902734-08-2, ISSN 1726-9679, Vienna, Austria

DOI: $10.2507 / 27$ th.daaam.proceedings.033

Bogdanovich A.V., Kirsanov K.B., Pryanichnikov V.E., Khelemendik R.V. HardwareSoftware components of intelligent service mobile robots / Information-measuring and control systems (Intelligent and adaptive robots, vol. 14, № 1-2, 2019), M.: Radiotechnika, 2018, vol. 16, № 12, p. 33-39. ISSN 2070-0814.

Bogdanovich A.V., Kirsanov K.B., Khelemendik R.V., Pryanichnikov V.E., Prysev E.A. (2018). Development of Technology for Manufacturing Hardware and Intelligent Levels of the Service Autonomous Mobile Robot AMUR-307, Proceedings of the 29th DAAAM International Symposium, pp.1313-1318, B. Katalinic (Ed.), Published by DAAAM International, ISBN 978-3-902734-20-4, ISSN 1726-9679, Vienna, Austria DOI: 10.2507/29th.daaam.proceedings. 189

Stepanova D., Pryanichnikov V.E., Khandorin S., Kuznetsov A., Koulchitskiy A. (2018). High-speed Image Processing Technique Implementation for Pointing and Tracking System Enabling Free-Space Optical Communications, Proceedings of the 29th DAAAM International Symposium, pp.1306-1312, B. Katalinic (Ed.), Published by DAAAM International, ISBN 978-3-902734- 20-4, ISSN 1726-9679, Vienna, Austria DOI: 10.2507/29th.daaam.proceedings.188 